Portland State University

PDXScholar

1990

\title{
Pragmatic conversational skills of children identified as emotionally disturbed
}

Deidre Winder

Portland State University

Follow this and additional works at: https://pdxscholar.library.pdx.edu/open_access_etds

Part of the Semantics and Pragmatics Commons, and the Speech and Hearing Science Commons Let us know how access to this document benefits you.

Recommended Citation

Winder, Deidre, "Pragmatic conversational skills of children identified as emotionally disturbed" (1990). Dissertations and Theses. Paper 4283.

https://doi.org/10.15760/etd.6166

This Thesis is brought to you for free and open access. It has been accepted for inclusion in Dissertations and Theses by an authorized administrator of PDXScholar. Please contact us if we can make this document more accessible: pdxscholar@pdx.edu. 
AN ABSTRACT OF THE THESIS OF Deidre winder for the Master of Science in Speech Communication: Speech and Hearing Sciences presented June $8,1990$.

Title: Pragmatic Conversational Skills of Children Identified as Emotionally Disturbed.

APPROVED BY THE MEMBERS OF THE THESIS COMMITTEE :
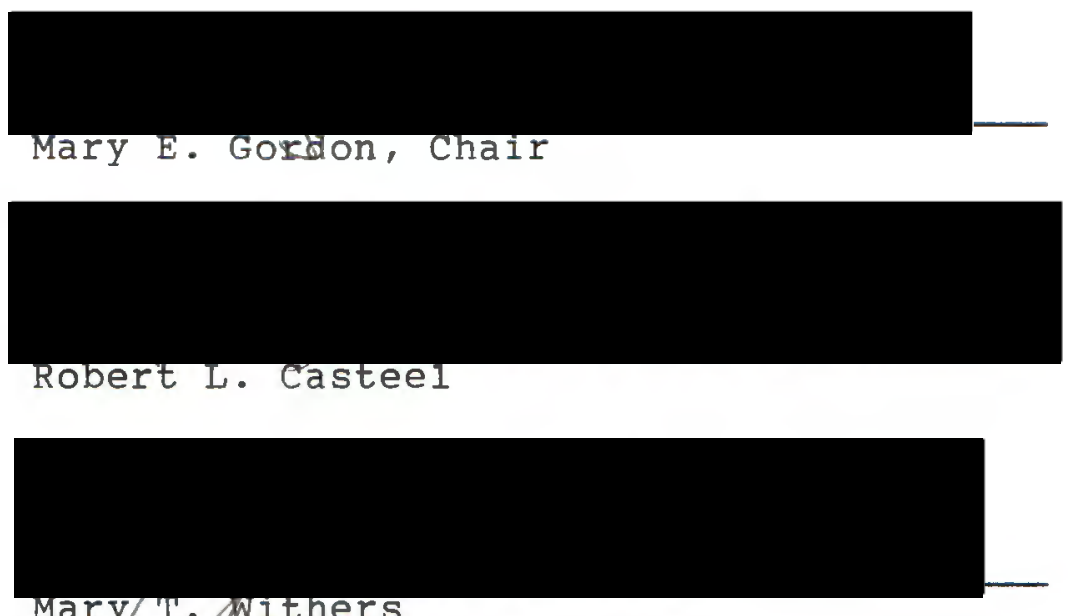

Communication refers to the conveyance of intended messages so that the listeners' attitudes, beliefs, or behaviors are changed. Communication through a language system may be thought of as the integration of the three components of content (semantics), form (syntax), and use (1anguage in context or pragmatics). The coming together of content, form, and use 
in signs, words, phrases, and discourse is the essence of language development. The synergism of content/form/use makes up language competence, or knowledge. When children speak and understand a message, they have a plan that is knowledge of language and they use that plan for the behavior involved in speaking or understanding messages, (Bates, 1976; Bloom and Lahey, 1978).

A review of the literature, at this time, finds an association between deficient language skills and children who are emotionally disordered. From their review of studies in 1988, Baltax and Simmons noted that the "domain of emotional disorders has only begun to be explored with respect to identifying pragmatic disorders." The authors contend that children who suffer from lags, deficits, or disorders in emotional development may be at risk for pragmatic development. With the exception of a published literature review of studies of pragmatic deficits in emotionally disturbed children by Baltax and simmons, (Audet, Burke, Hummer, Maher, and Theadore, 1990), there is little research that deals specifically with a pragmatic checklist and the appropriate and inappropriate pragmatic behaviors of emotionally disturbed children.

The purposes of this study were to compare, by use of the Pragmatic Protocol, the incidence of pragmatic disorders within a school-aged, emotionally disturbed population as compared to a control group of normal students and to 
specify the pragmatic areas, i.e., verbal aspects, paralinguistic aspects, and nonverbal aspects, in which deficits occur.

The twenty-eight, 6 to 10 year old subjects were students from the three-room school building housed on the grounds of a residential treatment facility in Multnomah county. All the subjects presented with normal intelligence and hearing acuity. The subjects were observed by way of videotaped conversations in two types of dyads. One conversational dyad was with a peer, another student at the treatment facility; the other conversational dyad was with a familiar adult, this investigator. Observation of the videotapes was then used to judge the pragmatic behaviors of the subjects as being appropriate or inappropriate utilizing the Pragmatic protocol.

The subjects were compared with a normal group from a study conducted by Prutting and Kirchner in 1987 who demonstrated a low incidence of pragmatic deficits (less than 1\%). The emotionally disturbed students demonstrated a significantly higher incidence of pragmatic deficits, $(x=$ $19 \%$ child-to-child dyads and $11 \%$ in child-to-adult dyads), with the highest percentage of inappropriate pragmatic behaviors for both dyads being specificity/accuracy and cohesion. Also within the top five highest percentage of error for both dyads were quantity/conciseness, eye gaze, and vocal quality. However there was no significant 
difference of the percentage of errors across the three aspects (verbal, paralinguistic, and nonverbal scales). In addition, emotionally disturbed children scored consistently on the Pragmatic Protocol regardless of conversational partner.

The findings from this sample, in both dyad types, support the literature which reports a high incidence of language disorders for emotionally disturbed children. Pragmatic skills are more inappropriate in this group compared to a group of normal students. Therefore, pragmatics is an important component of communicative competence to be considered in evaluation as well as in remediation of communication disorders. 
PRAGMATIC CONVERSATIONAL SKILLS OF CHILDREN IDENTIFIED AS EMOTIONALLY DISTURBED

by

DEIDRE WINDER

A thesis submitted in partial fulfillment of the requirements for the degree of

\author{
MASTER OF SCIENCE \\ in \\ SPEECH COMMUNICATION: \\ SPEECH AND HEARING SCIENCES
}

Portland State University

1991 
TO THE OFFICE OF GRADUATE STUDIES:

The members of the Committee approve the thesis of Deidre Winder presented June 8, 1990.
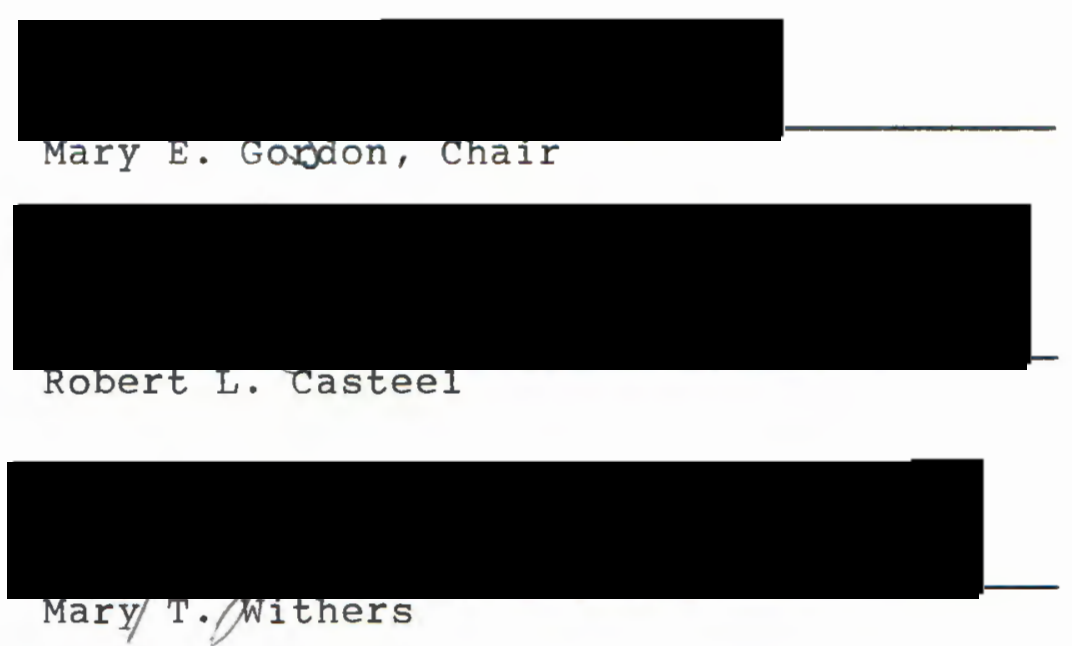

APPROVED :

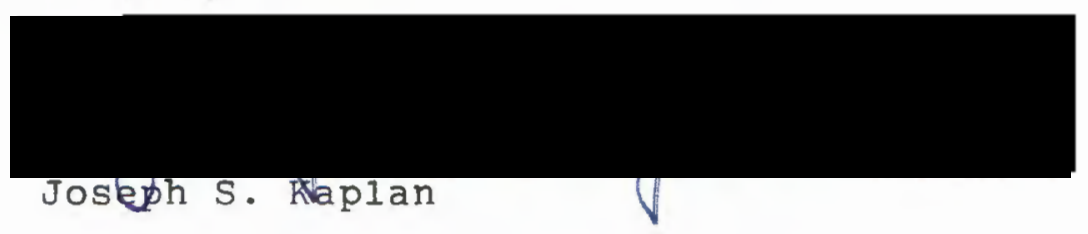

Theodore G. Grove, Chair, Department of Speech communication and Research 


\section{ACKNOWLEDGEMENTS}

Any important undertaking is seldom achieved by one individual alone, but rather by a network of individuals and talent that contribute to the end result. such is this thesis; therefore, I would like to thank the following: -Dean Winder and Mary Gordon who made me feel this was indeed possible.

-Shane and Kassie winder who have shared their mother with her own goals at PSU and her career in Portland Public Schools.

-R.D. and Kathy Eiland, my parents, who have continuously lent their support, emotionally and financially.

-The magic fingers of Linda Edwards, Barbara Colburn, Barbara Vogelsang, and Eileen Mueller.

THANK YOU! IT IS FINISHED! 
TABLE OF CONTENTS

PAGE

ACKNOWLEDGEMENTS

LIST OF TABLES . . . . . . . . . . . . . . .

vi

LIST OF FIGURES.

I INTRODUCTION AND STATEMENT OF PURPOSE. .

Introduction. . . . . . . . . . . . 1

Statement of Purpose. . . . . . . . . 2

Operational Definitions . . . . . . 3

II REVIEW OF THE IITERATURE . . . . . . . 5

Introduction . . . . . . . . . 5

Development of Pragmatic skilis: : 6

Language Abilities of Children with

Assessment. . . . . . . . . . . . 13

III METHODS . . . . . . . . . . . . . 18

Subjects. . . . . . . . . . . . 18

Selection Criteria. . . . . . . . 18

Evaluation Instrument . . . . . . 20

Procedures. . . . . . . . . . . 20

Data Measurement and Analysis . . . 23

IV RESULTS AND DISCUSSION . . . . . . . 25

Results . . . . . . . . . 25

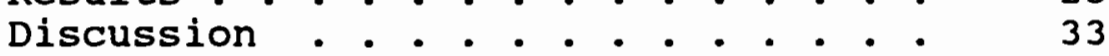

V SUMMARY AND IMPLICATIONS ......... 38

Summary . . . . . . . . . . . 38

Implications .......... . 41 
APPENDICES

A PRAGMATIC PROTOCOL . . . . . . 47

B DEFINITIONS FOR COMMUNICATIVE

PARAMETERS ASSESSED USING THE

PRAGMATIC PROTOCOL • • • 


\section{LIST OF TABLES}

TABLE

PAGE

I Mean (M), Standard Deviation SD, Range of Appropriate Pragmatic Aspects Language, and Rank Order of Most Frequent Inappropriate Pragmatic Aspects per Group Expressed in Percentages . . . . . . . . . . 26

II Comparison of Aspects Between the

Emotionally disturbed subjects in

Both Dyad Types and the Normal Group.

III Mean Scores (M), Standard Deviations (SD), t-Values for the Child-Child Dyads and Child-Adult Dyads between Verbal Aspects and Non-Verbal Aspects. . . . . . . 34 


\section{LIST OF FIGURES}

FIGURE

PAGE

1. Comparison of percentage of inappropriate pragmatic parameters per aspect, by groups . • • . • . • • . . • . 27

2. Pragmatic parameters marked inappropriate

for the 28 emotionally disturbed students in the child-to-child Dyad. . 30

3. Pragmatic parameters marked inappropriate . for the 28 emotionally disturbed students in the child-to-adult dyad. . 
CHAPTER I

INTRODUCTION AND STATEMENT OF PURPOSE

\section{INTRODUCTION}

Pragmatics, as defined by Bates (1976), is the use of language in context. Communicative competence depends on how effectively a person translates cognitive and social knowledge into linguistic forms, depending on the specific situation and the ability to follow pragmatic rules. Pragmatic development culminates in the ability to participate in a conversation. Conversational skills are currently an area of focus for most speech-language pathologists involved in the assessment of communicative competency in school-aged children.

Speech-language pathologists in the public schools work with a variety of populations. Since the enactment of Public Law 94-142 and the subsequent emphasis on mainstreaming, clinician caseloads can include students with the handicapping condition of emotional disturbance. Emotionally disturbed students display a variety of speech/language disorders, including articulation, voice, stuttering, and language. Recent studies address the above areas, but this reviewer of the literature found little published research relative to the pragmatic skills of emotionally disturbed 
children. Baltax and Simmons (in Schiefelbusch and Lloyd, 1988), believe that the emotionally disturbed population has just begun to be studied with respect to identifying pragmatic deficits (Schiefelbusch and Lloyd, 1988). The ability of emotionally disturbed students to communicate in conversation is critical to appropriate social skills, successful academic performance, and most importantly, to realization of counseling/therapy goals. Therefore a need exists to compare the conversational abilities of emotionally disturbed children to a normal group to determine if the former exhibit significant difficulties in the area of language use.

\section{STATEMENT OF PURPOSE}

The purpose of this study was to investigate the conversational abilities of children housed in a residential facility and identified as emotionally disturbed by utilizing the Pragmatic Protocol (Prutting and Kirchner, 1987). The questions this investigation posed were:

1. How do elementary age students identified as emotionally disturbed perform on the Pragmatic Protocol during a conversational interaction with (a) an adult and (b) a peer?

2. Do children identified as emotionally disturbed display a significant difference in their performances among the three areas assessed by the 
Pragmatic protocol, i.e., the verbal aspects, the paralinguistic aspects, and the nonverbal aspects? The first question was investigated by comparing the emotionally disturbed subjects with a normal group and by comparing the two dyad groups, i.e., child-to-child and child-to-adult.

\section{OPERATIONAL DEFINITIONS}

The following operational definitions were used for this study:

1. Aspect/Parameter: one of 30 communicative skills in the pragmatic protocol, e.g., selection, introduction, and maintenance. Each aspect was included under one of the following categories: verbal, paralinguistic, and nonverbal (Prutting and Kirchner, 1987).

2. Emotionally Disturbed: describes children who may be aggressive, destructive, withdrawn or depressed. They have difficulty with relationships; are angry, hostile, unable to trust and have poor self images. These children come from dysfunctional family systems and most of them have been neglected or abused, sexually and/or physically. often, they have had multiple foster and school placements. These children have severe behavioral and deep-seated emotional problems requiring long-term 
therapy, with an average residential stay of two years (From Treatment Facility Informational Pamphlet, 1989).

3. Illocutionary Acts: The intentions of the speaker (Gallagher and Prutting, 1983).

4. Nonverbal Aspects: use of nonverbal aspects of communication (eye gaze, gestures, body posture, etc.) that demonstrate level of affiliation between partners, aid in regulating discourse turns, and may supplement or support linguistic aspects of the message (Prutting and Kirchner, 1987).

5. Paralinguistic Aspects: factors pertaining to the quality of speech, i.e., show appropriate use of intonation, stress, and pitch to support the communicative/linguistic intention of the message (Prutting and Kirchner, 1987).

6. Perlocutionary Acts: effects of the message on the listener (Gallagher and Prutting, 1983).

7. Propositional Act: the linguistic dimensions of the meaning of the sentence (Gallagher and Prutting, 1983).

8. Utterance Act: the trappings by which the act is accomplished (Gallagher and Prutting, 1983).

9. Verbal Aspects: the ability to take both speaker and listener roles, appropriate to the context (Prutting and Kirchner, 1987). 


\section{CHAPTER II}

REVIEW OF THE LITERATURE

\section{INTRODUCTION}

In order to define language, one must identify its components. Bloom and Lahey (1978) proposed that language is three-dimensional, consisting of content or meaning that is represented by linguistic form for some purpose or use in a particular setting or context. In a normally developing child, linguistic competence of form implies a knowledge of constructing grammatically acceptable sentences. Form, then, is the linguistic code for representing language content. The child's cognitive and semantic development provides the basis for these linguistic patterns. Form is composed of units of sound, phonology; the units of meaning that are words or inflections, morphology; and the ways in which units of meaning are combined with one another or syntax. The area of content includes semantics or word knowledge, i.e., the acquisition of vocabulary. The child is learning about the world and putting that information into the words or syntactical constructions of a message. According to Gleason (1985), as critical as these two competencies (i.e., form and content) are for a child, "speakers who know how to use language appropriately have 
more than linguistic competence; they have communicative competence" (p. 22). Pragmatics is the ability to express needs, i.e., a means to an end and/or intent, including the ability to speak appropriately in varying social situations (Prutting, 1982; Warren-Leubecker and Bohannon, 1985).

\section{DEVELOPMENT OF PRAGMATIC SKILLS}

Bloom and Lahey (1978) pointed out the importance of pragmatic language development when they stated, "languages exist because of the functions they serve; therefore, how children learn to use language for such different purposes as to get and give information and initiate and monitor interactions with others is a major aspect of their development" (p. 201).

Before citing some developmental milestones of pragmatics, it is necessary to consider context which, according to Prutting (1982), is the core of pragmatics. In a broad sense, context may be thought of as the interrelated conditions in which something exists or occurs. As with the development of language form and content, the development of language use is a result of the interaction between children and contexts. In other words, children's needs change in relation to the changing situation in their environments (Bloom and Lahey, 1978; Prutting, 1982). If children are going to send a message or respond to another's message, they must integrate cognitive and social knowledge with 
linguistic knowledge, following pragmatic rules (Bloom and Lahey, 1978; Prutting, 1982). Prutting stated that social and cognitive knowledge involves "the physical world and social world, including the setting, the communicative partner and the rules for interaction" (1982, p.42).

Prutting (1982) outlined four major areas of pragmatic development: (1) prerequisite cognitive and social behavior, (2) functions of language in context that serve the child's purposes, (3) conversational rules within linguistic and non-linguistic contexts, and (4) stylistic variations within social contexts. This outline will provide the framework for presenting information about the normal acquisition of pragmatics.

Under the area of prerequisite cognitive and social behavior, Bates (1979) emphasized the intertwining among social maturation, cognitive growth, and language acquisition. She indicated that two important skills begin to emerge between the ages of 9 and 13 months that permit children to communicate by symbols (language): (1) the onset of communicative intentions and conventional signals, and (2) the emergence of symbols and the discovery that objects have names. Indicators for the beginning of communicative intent, as stated by Bates (1979) and Bruner (1975), involve eye contact, checks for feedback, and changes in signaling until the goal is met. Possible indicators for the emergence of symbols may include the 
cognitive ability of object permanence and the cause-effect relationship, as well as linguistic ability to recognize the relationship between an object and its label or name.

Examining functions of language in context, Dore (1975) developed a classification of primitive speech acts based on the child's perception of the situation (i.e., the physical surroundings and relationship with the other person). The child uses language to achieve a purpose. Based on his observations of three 1-year olds interacting with adults, Dore's system for specifying functions of language use included labeling, repeating, answering, requesting an action, requesting an answer, calling, greeting, protesting, and practicing.

Looking at emergence of conversational rules, such as revision, requests for clarification, turn taking, etc., Lucas (1983) reported the results of a longitudinal study that examined the nature of adjacency in adult-child responses. Adjacency was defined as an utterance following another in time. It was found that by age 3 , children use contingent responses which are responses that relate to the prior utterance. They also add information, use fewer imitative responses, and more self-initiated utterances. Lucas concluded that, as children grow older, they use more effective conversational strategies. Also, by the age of 3 , children show some sensitivity to the needs of others in conversation and are capable of revising their utterances 
to repair communication breakdown in conversations. Beyond the age of 4 , turn-taking skills in conversation become refined as children increase interest in a partner's topic, show a desire to have a turn and not be ignored, and improve in processing skills with increasing age (Lucas, 1983).

As children increase skills in using language, they develop an ability to interact in a conversation with a variety of partners (Schwabe, Olswang, and Kriegsmann, 1986). Registers are the type of linguistic variation most related to this basic social function of language. Registers fall within the last of Prutting's (1982) four major areas of pragmatic development and are defined as stylistic variations within a social context (Nicholson, 1983; Warren- Leubecker and Bohannon, 1985). By age 4, children will adjust their speech for different conversational partners. Leonard and Reid (1979) studied forty 3 to 6-year olds and their judgments of appropriateness of utterances. They observed that children around the age of 4 begin to judge correctly if an utterance is appropriate to the context. By 6 years of age, judgments of appropriateness consider more adult-like criteria.

As seen throughout the above summary, preschool children become increasingly more adept at using different strategies to repair communication breakdowns, convey specific information, and direct and follow the topic of conversation. Research indicates that basic pragmatic 
conversational skills are generally acquired by age 6 and children are able to communicate their goals within a conversational framework by age 7 or 8 . Beyond this age, as they develop cognitively and socially and increase their vocabulary, children continue to refine these basic pragmatic conversational skills in more subtle ways (Nicholson, 1983; Parnell and Amerman, 1983; Prutting, 1982).

LANGUAGE ABILITIES OF CHILDREN WITH EMOTIONAL DISTURBANCES

with emotionally disturbed children, Bloom and Lahey (1978) contended there is a disruption in interaction of use with the areas of form and content. The children code ideas, but use language for inappropriate purposes and only rarely for interpersonal communication. Bloom and Lahey (1978) observed, "while many emotionally disturbed children produce grammatical utterances, the form is often deviant in its relationship to content and use" (p. 518). For example, a student replied, "I don't know I wasn't watching," when asked, "How did you get to the concert?"

A review of studies finds much of the literature deals with a specific category of emotional disturbance and the broad category of "language." With the exception of Baltax and Simmons (in Schiefelbusch and Lloyd, 1988) who contended that children who suffer from lags, deficits, or disorders in emotional development may be at risk for pragmatic deficits, few studies deal specifically with language use 
and the emotionally disturbed. Many of these studies have investigated autism and childhood schizophrenia (Ornitz and Ritvo, 1976; Rutter, 1983; Shapiro and Huebner, 1976). A study by Shapiro, Chiarandini, and Fish (1974) suggested that closer evaluation of language behavior alone will not only increase understanding of the structure of childhood schizophrenia, but provide better models for understanding the disorder and its varying prognosis. In a reverse research design of the above-mentioned studies, which looked at the association of language deviance with psychological labels such as autism, Baker and Cantwell (1982) looked at psychiatric disorders in children with different types of communication disorders. They found that $95 \%$ of pure language-disordered children displayed some kind of behavioral disorder. The most frequently occurring disorders included attention-deficit disorder, avoidant behaviors, oppositional disorder, separation-anxiety disorder, adjustment disorders, conduct disorders, and affective disorders.

More recently, Camarata, Hughes, and Ruhl (1988) found that 37 out of a group of 38 children labeled mild to moderately behavior-disordered, fell at least one standard deviation below the mean on one or more of the TOLD-I subtests. More importantly, a review of case files on each of the subjects indicated only 2 of the 38 subjects (fewer then 6\%) had been seen for services by speech-language patholo- 
gists and none had received formal language assessment from qualified professionals.

The above-cited studies reported a high correlation between behavioral/emotional disorders and language delays/ disorders. The next logical area to examine is why do these children show these delays? Allen and Wasserman (1985) looked specifically at the mothers of abusing mother-infant pairs. This study found that abusing mothers rarely label objects, ask questions of their children, or explain aspects of the environment. The authors estimated that an abused toddler receives one-half the verbal stimulation that a nonabused child receives. Abusing mothers and abused children also tend to ignore each other. The Bayley Mental Development scale (Bayley) (Bayley, 1969), provided the main measure of language skills for the abused children and a control group. The Bayley is a widely used standardized infant development test which has been shown to correlate positively with measures of early language development and the Stanford Binet. All infants under 14 months had normal Bayley scores and control infants over 14 months continued to have normal scores. However, abused children over 14 months had an average Mental Development Index of 63 (normal = 100), demonstrating significant delays.

Past and present therapeutic programs for abused and/or behavioral/emotionally disturbed children have typically not included intensive language stimulation, but rather have 
focused on behavioral and/or emotional issues (Allen and oliver, 1982). The results of the previously mentioned studies indicate a need for language intervention to compensate for the effects of inadequate language stimulation.

\section{ASSESSMENT}

Considering the complexities of conversation and the many behaviors which can occur during an interaction, it is necessary to organize the pragmatic conversational behavior into a systematic format. Miller (1978), Prutting (1982), and Wiig (1982) have done this in different ways.

Miller's (1978) model for analyzing children's pragmatic structures is best suited for preschool children at the level of symbolic play. The instrument is utilized during half-hour samples of interactions between a clinician and three children in a play situation with consideration of communicative interaction and strategies. The assessment tool describes two main types of information, i.e., communicative interaction and communicative strategies. Under the communicative interaction category, Miller included examining the relative dominance of a speaker's quantity of verbal and nonverbal turn taking and length of turn per person, number of topic switches, and number of communicative breakdowns and repairs of conversation. Under the categories of communicative strategies, she included the individual 
pattern of communication including the use of gestures, facial expression, intonation, verbal language, syntax, and semantic categories.

wiig (1982) has developed an evaluation instrument to assess strengths and weaknesses in the interpersonal verbal communication skills of adolescents. The inventory looks at the ability to formulate or identify context-appropriate communication functions and speech acts. Wiig states, "This inventory is biased, and biased purposefully, in the direction of probing for the ability to formulate and interpret context-appropriate speech acts within the context of expectations for speakers of standard American English" (1982, p. 2).

In contrast, Prutting's (1982; Prutting and Kirchner, 1987) Pragmatic Protocol is not limited to one stage of development, but provides an overall communicative index for school-aged children, adolescents, and adults. The tool was designed to be used with subjects 3 years of age or older since the developmental literature suggests that by this age children show some form of all 30 parameters on the protocol. Both the 1982 and 1987 versions judge 30 pragmatic behaviors as being appropriate or inappropriate within a given conversational interaction. Based upon Searle's (1969) and Austin's (1962) speech act theories, Prutting's (1982) original protocol was divided into three parts of a speech act:

(1) utterance (actual production of 
sounds to represent ideas); (2) propositional (linguistic dimensions of the meaning of the sentence); and (3) illocutionary (intentions of the speakers)/perlocutionary aspects (effects on the listener).

The behaviors under the utterance act category include verbal dimensions such as fluency and voice quality, and nonverbal dimensions such as eye gaze and gesture; both of these dimensions are involved in the act of uttering words. The behaviors under the propositional act category involve the linguistic dimensions of the message, such as word order and word accuracy. The behaviors under the illocutionary/ perlocutionary act category handle the interactional aspects of a conversation, such as the ability to use speech acts appropriately and other factors involving the mechanical aspects involved in turn taking and handling of topic. In 1987, Prutting and Kirchner abandoned the discrete classification of parameters under one of these three speech act categories. They believed intentionality and meaning are at the core of language use and, therefore, there is a lack of boundaries that distinctly separate propositional knowledge, for example, from illocutionary function. When selecting the items, Prutting and Kirchner included the following four criterion properties when constructing the protocol: (1) inclusiveness or broadness of scope; homogeneity, which means all parameters represent a logical relationship to communicative competence and to each other; 
(3) mutual exclusiveness, which means all items refer to one unique dimension of communicative competence and can be classified into only one category; and (4) usefulness, which means each parameter serves a function in relation to the purpose of study.

Each item on the protocol was included under one of three categories, i.e., verbal, paralinguistic, and nonverbal (see Appendix $A$ ). The verbal aspects include the ability to take both speaker and listener roles using a variety and diversity in what one can do with language (e.g., assert and request), as well as the ability to make relevant contributions to a topic. Also included under this category is lexical selection or the use of lexical items that best fit the text or discourse. Cohesion and stylistic variances under verbal aspects deal with relationships between and across speech acts and the ability to adjust speech style to the listener. Paralinguistic aspects pertain to speech that is clear; not too loud or too soft; appropriate in vocal quality with appropriate intonation, stress, and pitch to support the communicative competency of the message. The use of nonverbal aspects of communication demonstrate an affiliation between speaker and listener aiding in regulating discourse turns and may supplement or support linguistic aspects of the message. Utilizing the Pragmatic Protocol provides a quick procedure that evaluates a range of pragmatic deficits and 
strengths within a conversational setting. The protocol gives professionals a pragmatic dimension that interacts with other measures in diagnosing a child's communication skills/disorders. 


\section{CHAPTER III}

\section{METHODS}

SUBJECTS

The 28 emotionally disturbed subjects who participated in this study were students from the three daytime classrooms which are part of a residential program located in Multnomah County, oregon. Subjects ranged in chronological age from 6 years, 4 months to 10 years, 10 months with a mean age of 8 years, 5 months. Of these 28 students, 9 were female and 19 were male. The three classrooms located at the facility are grouped according to social/emotional development. The developmental ages ranged from approximately 3 years to 9 years. The school program offers a basic elementary curriculum with related educational services as defined by an individualized education plan for each student. Regular and special education materials are utilized with teachers offering instruction in large group, small group, and individualized formats.

\section{SELECTION CRITERIA}

Subject selection for the emotionally disturbed sample was determined by their eligibility for admittance to the residential treatment program. The subjects come from a 
variety of dysfunctional homes/families, have been sexually and/or physically abused or neglected, and have often had multiple foster home and school placements. These children have severe behavioral and deep-seated emotional problems requiring long-term therapy. The majority of these children are placed in the treatment center by oregon state children's Services Division. Often the children present with emotional issues listed on The Diagnostic and Statistical Manual of Mental Disorders-III (a classification system for diagnostic categories and criteria for diagnosis of adult and childhood psychiatric disorders), but have not yet been given a fixed label such as schizophrenia. Children's Services Division has ascertained these children likely cannot function outside of a residential treatment facility. The average residential stay is two years.

In addition, all subjects had passed a pure tone audiometric screening within the past year for the frequencies of $500,1000,2000$, and $6000 \mathrm{~Hz}$ at $20 \mathrm{~dB}$ for both ears. None of the subjects had a diagnosis of severe physical or sensory handicapping condition, such as cerebral palsy or blindness, which may have interfered with verbal and nonverbal abilities. Intelligence or an IQ score was not a selection criteria, unless at some time the student had been labeled mentally retarded, educable mentally retarded, or trainable mentally retarded. In such cases, these students were not included in the study. 


\section{EVALUATION INSTRUMENT}

The Pragmatic Protocol, designed by Prutting (Prutting and Kirchner, 1987), describes the pragmatic or language use skills involved in conversational interactions. The protocol focuses on three aspects of communicative interaction: verbal aspects, paralinguistic aspects, and nonverbal aspects. Combined, the three categories consist of 30 specific behaviors outlined in the protocol, (see Appendix A). Definitions and references for each of the specific communicative parameters are listed in Appendix B.

The Pragmatic Protocol provides a means of qualitatively assessing a subject's interactions as "appropriate," "in-appropriate," or "not observed." These judgments are made by the evaluator in consideration of the communicative setting and the relationship or stylistic variation between the conversational partners.

\section{PROCEDURES}

\section{Training Procedures}

In order to fulfill permission requirements in using the aforementioned residential population, the only judges involved in establishing reliability for this study included this investigator and the Director of the Speech and Hearing Sciences Program at Portland State University, who has held the Certificate of clinical Competence in speech-Language 
Pathology since 1967, and who has had previous experience using the protocol.

An article on pragmatics by Prutting and Kirchner (1987) and a handout describing behaviors on the Pragmatic Protocol (Appendix B) were read and discussed by the two judges to evaluate videotapes of conversational dyads. Then the two judges used the Pragmatic Protocol to evaluate ten dyads. Any discrepancies in scoring were discussed and the rating procedure was repeated with other dyads. This process was continued until interjudge reliability for each dyad was .85 or better on the last ten dyads evaluated.

The training tapes consisted of adult-adult dyads, child-adult dyads, child-child dyads, and language disordered child-adult dyads, as well as some training tapes consisting of students and a classroom teacher at the residential facility. None of these training samples contained data for this study.

Reliability was calculated using the following formula:

$\frac{\text { agreements }}{\text { agreements + disagreements }} \quad$ X 100

The mean reliability rating between the investigator and the clinical supervisor for 10 dyads was $93 \%$.

The intrajudge reliability rating was determined by comparing the investigator's scoring on a set of four dyads from the training session with the investigator's scoring these same tapes approximately two weeks later. 


\section{Investigation Procedures}

To collect the data for this study, a Panasonic single Camera Recording system (AG-100) was used to record the conversational interactions of the subjects. The camera was attached to a tripod set approximately 4 to 6 feet from the table where the conversation took place. All of the subjects were familiar with the camera and equipment which had been previously used in the classrooms. Either individually or in the classroom, simple parts of the camera were pointed out, such as the lens and microphone, and the subjects were given the opportunity to ask questions about the equipment and its use prior to the actual taping.

Each subject was videotaped with two communicative partners, i.e., the investigator and a randomly selected peer; both partners were familiar to the subject. The subject and communicative partner were taped for a minimum of 5 minutes with an average taping time of 6 minutes. students were given the following directions immediately prior to conversing with the investigator: "You and I are going to talk to each other for a few minutes." When the students were to talk with a peer, they were instructed, "talk with (student's name) for a few minutes." The students who asked about or stared at the camera were told the camera was there to help the investigator remember what was said. The students, who requested it, were allowed to 
see themselves on videotape after the conversation was completed.

\section{DATA MEASUREMENT AND ANALYSIS}

The tapes were then reviewed by the investigator and spontaneous conversational interactions were judged using the Pracmatic Protocol.

\section{Reliability}

The Director of the Speech and Hearing sciences Program reviewed $25 \%$ of the videos in order to determine reliability of the protocol scoring. Interjudge reliability was $90 \%$ for the tapes reviewed.

Intrajudge reliability, which was established two weeks after the initial viewing of the videos, was 93\%. To further enhance confidence of correctness of scoring, the investigator consulted with the director, relevant to any questions regarding scoring/rating of inappropriate responses.

\section{Data Analysis}

The results of scoring each subject's appropriate and inappropriate behaviors on the protocol were tabulated and then analyzed using descriptive statistics. These analyses included subject group comparisons of the mean percentage of appropriate pragmatic parameters and within group measures that addressed the patterns of deficits in each subject 
group. In particular, the rank order of the five pragmatic parameters most frequently marked inappropriate, as well as individual subject data that reflects profiles of performance across all 30 communicative parameters was determined. t-test comparisons were conducted between the emotionally disturbed subjects in both dyad types and the normal group. Also compared were $t$-values for the childto-adult dyads and child-to-child dyads between the verbal aspects, paralinquistic aspects and nonverbal aspects. 
CHAPTER IV

RESULTS AND DISCUSSION

\section{RESULTS}

The purpose of this study was to investigate the conversational skills of children identified as emotionally disturbed, using the Pragmatic Protocol. The first question asked was, how do elementary-aged students, who have been identified as emotionally disturbed, perform on the Pragmatic Protocol during two different conversational interactions, one with an adult and one with a peer? This question was answered using descriptive, as well as inferential, statistical analysis.

In order to provide a comparison, a normal group was used as a control. The data for this group were collected as part of a study conducted by Prutting and Kirchner (1987). The normal children showed few inappropriate pragmatic behaviors (less than 18 on the average). The small standard deviation $(S D=3.0)$, as shown in Table $I$, indicates little variability within this group. In comparison, for the emotionally disturbed child-to-child dyad, the mean score was 848 , which is 17 percentage points below the mean of the normal group, with a higher standard deviation $(S D=16)$, indicating more variability within this 
group. This variability, when compared to the normals was also noted in the emotionally disturbed students in the child-to-adult dyad with a mean score of $85 \%$ (S.D. = 15).

\section{TABLE I}

MEAN (M), STANDARD DEVIATION (SD), RANGE OF APPROPRIATE PRAGMATIC ASPECTS OF LANGUAGE, AND RANK ORDER OF MOST FREQUENT INAPPROPRIATE PRAGMATIC ASPECTS PER GROUP EXPRESSED IN PERCENTAGES.

\begin{tabular}{lll}
\hline Group M SD Range & $\begin{array}{l}\text { Rank order of } \\
\text { inappropriate } \\
\text { aspects }\end{array}$
\end{tabular}

Normal Children $(\mathrm{N}=42) 99 \quad 3 \quad 83-100$

Child w/Child $(\mathrm{N}=28) \quad 84 \quad 16 \quad 40-100 \quad$ Specificity/ Accuracy (43\%) Cohesion (39\%) Body Posture (36\%) Eye Gaze (28\%) Quantity/ Conciseness Vocal Quality $(25 \%)$ Physical Proximity (25\%)

Child w/Adult $(\mathrm{N}=28) \quad 85 \quad 15 \quad 47-100 \quad$ Specificity/ Accuracy (57) Cohesion (57\%) Quantity/ Conciseness (32\%) Vocal Quality (32\%) Eye Gaze (32\%)

For further differentiation, the percentages of inappropriate behaviors per aspect were determined for the normals, child-to-child dyads, and adult-to-child dyads (Figure 1, p. 27). 


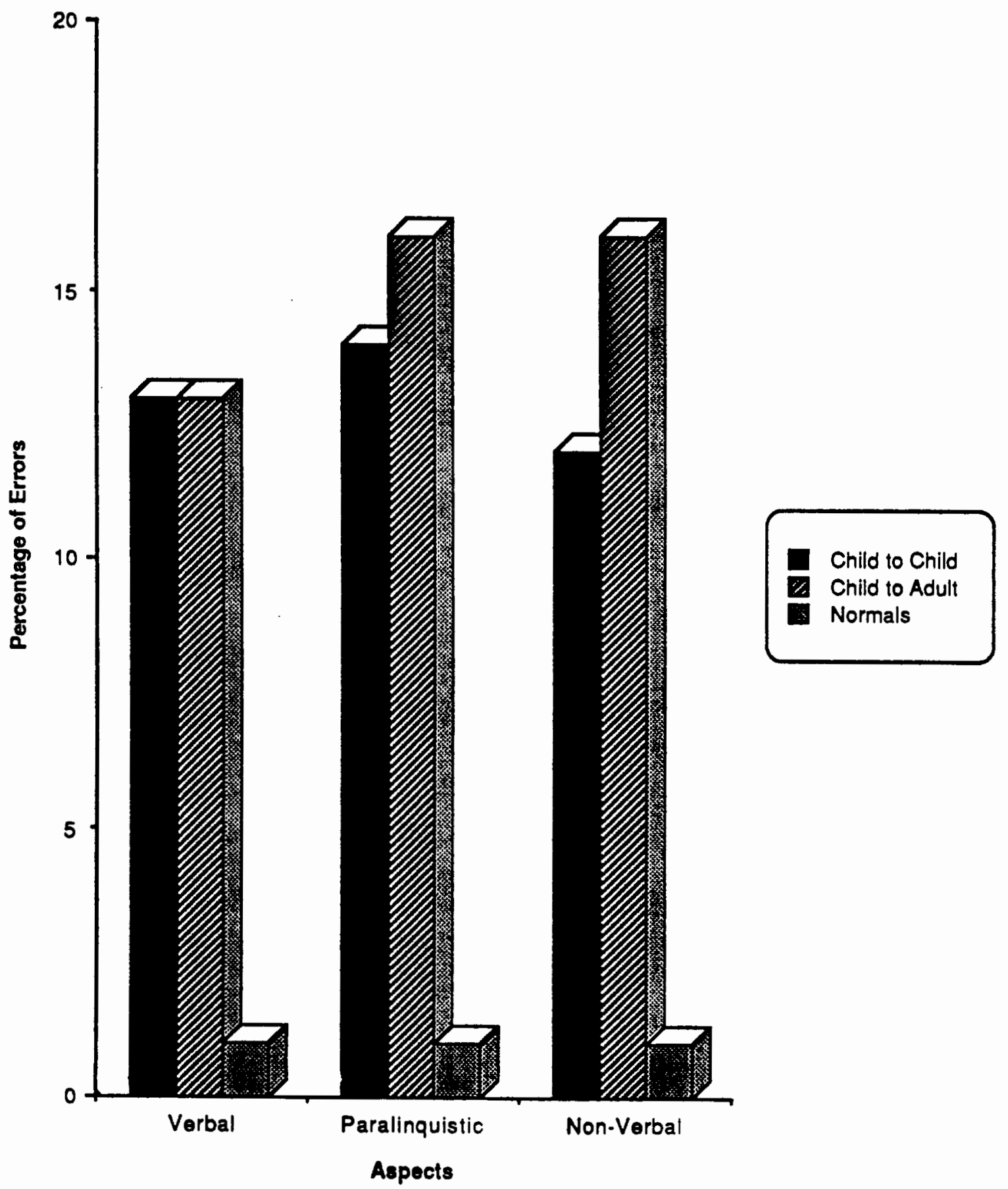

Figure 1. Comparison of percentage of inappropriate pragmatic parameters per aspect, by groups. 
The Profiles of pragmatic deficits of the normal dyads were compared with the profiles of the emotionally disturbed subjects for each "scale" or aspect of the Protocol using 2-tailed $\underline{t}$-tests for independent means. Results showed a statistically significant difference on all three scales (i.e., verbal aspects, paralinguistic aspects, and nonverbal aspects) between the emotionally disturbed subjects in both dyad types and the normal group (Table II, p. 29). The emotionally disturbed students displayed a significantly greater percentage than the normals of inappropriate behaviors across all three scales beyond what would be expected by chance.

Emotionally disturbed students were found to be deficient on a cluster of responses that relate to issues of the Verbal Aspects, particularly specificity/accuracy and cohesion. Individual subject profiles that reflect these clusters of inappropriate responses are presented in Figures 2 and $3, \mathrm{pp} .33$ and 34 . To further describe the pragmatic behaviors of the emotionally disturbed subjects, the rank order of the five pragmatic parameters most frequently marked inappropriate per dyad type were determined. In the child-to-adult dyads, rank order of inappropriate aspects was as follows: specificity/accuracy, the use of unspecified referents such as, "stuff," "thing," etc., (57\%); cohesion, the inability to take a listener through an event in a logical, sequential manner (57\%); quantity/conciseness, 

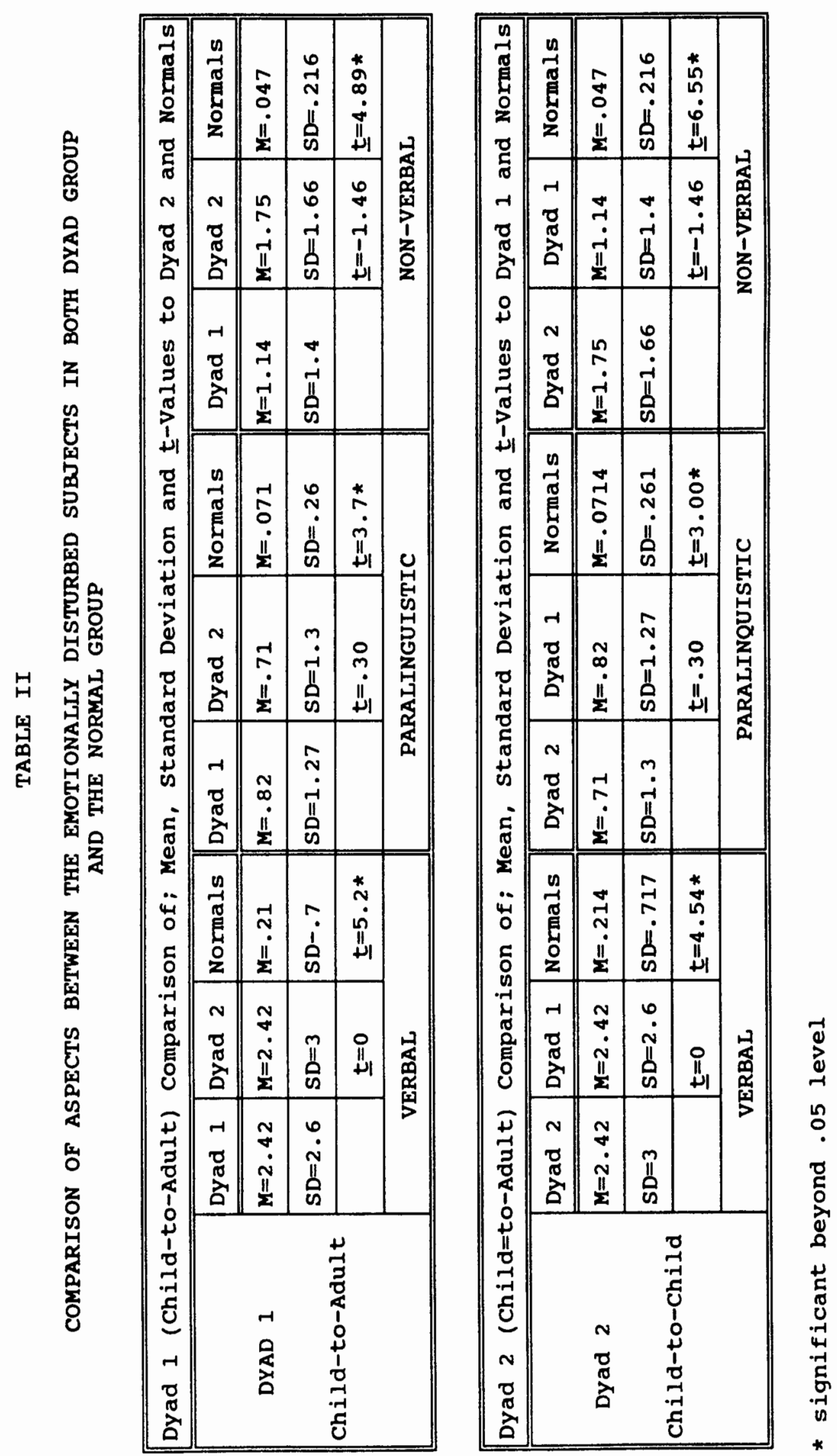


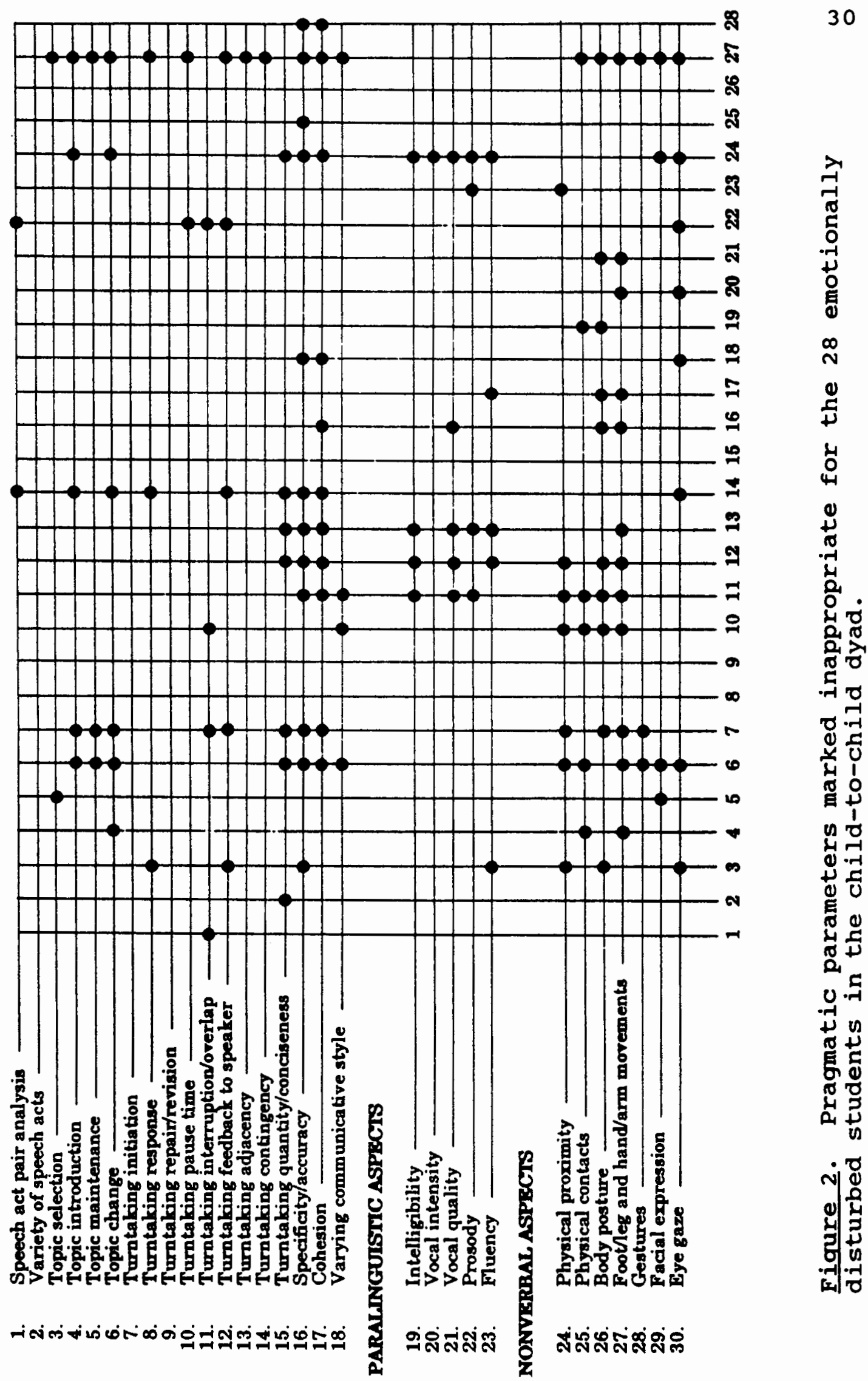




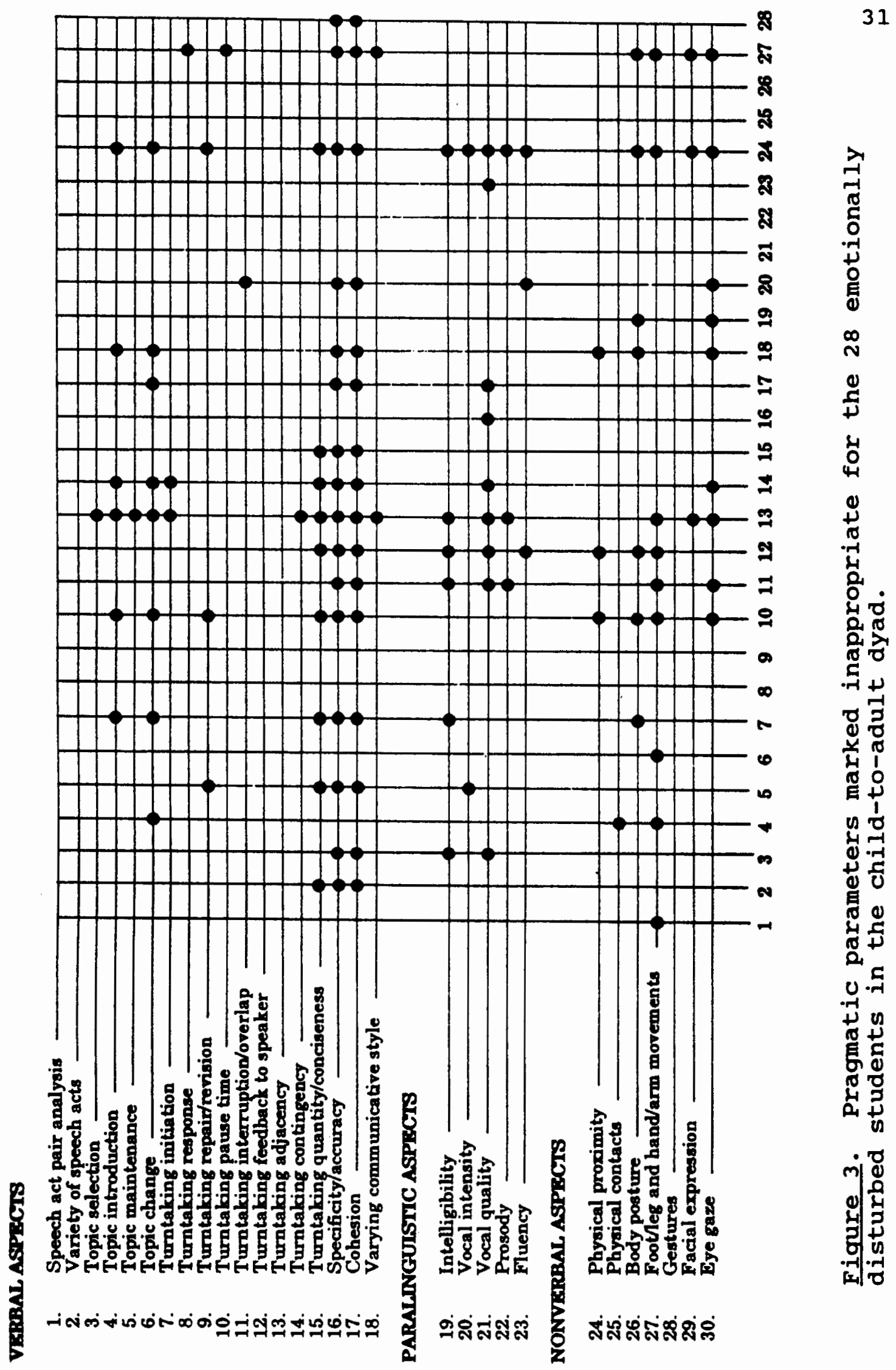


little initiation in the conversation or just as often, not giving the listener a chance to be a speaker (32\%); vocal quality, often the listener perceives the speaker to have a breathy, hoarse quality to their speech (32\%); and eye gaze, not glancing at the conversational partner's face (32\%). For the child-to-child dyads, the following rank orders of inappropriate aspects was noted: specificity/accuracy (43\%); cohesion (39\%); body posture, for example, slouching, excessive side to side movement (36\%); eye gaze (28\%); and quantity/conciseness, vocal quality and physical proximity one subject moving too close to another or moving too far away (all at $25 \%$ ). These results are presented by group in Table I.

The second question posed was: Do children identified as emotionally disturbed display a significant difference in their performances among the three areas assessed by the pragmatic protocol, i.e., the verbal aspects, the paralinguistic aspects, and the nonverbal aspects? Descriptive statistics for this research included the percentage of inappropriate behaviors per subject for each of the three aspects. For inferential statistics, a pooled variance $\underline{t}-$ test was calculated to determine if there was a patterning of inappropriate pragmatic behaviors in each of the three scales, representing more than chance variation.

Results were not significant as shown in Table III; however, an examination of the mean differences in the 
child-to-child dyad (verbal aspects $=88.679$, paralinguistic aspects $=86.429$, and nonverbal aspects $=77.50$ ) deserved further analysis to determine if there was a significance of patterning within this one group. Analysis of variance was used, to examine this group difference, by looking at all three aspects together. There was no significant difference among aspect scores for child-to-adult dyads (F Prob. = .1356). These results indicate there was no significant patterning of inappropriate pragmatic behaviors in any of the three scales and distribution of pragmatic deficits was fairly evenly distributed across all three categories.

\section{DISCUSSION}

This study looked at the conversational skills of emotionally disturbed students, who were in a residential treatment facility, in an attempt to add information to recent studies indicating poor language skills for this population. The results of this investigation suggest that emotionally disturbed, school-age children have pragmatic or conversational skills that are inappropriate, especially as compared to their normal peers.

A descriptive analysis of percentage of error of inappropriate responses within the emotionally disturbed groups yielded the same parameter as the most frequently inappropriate for each dyad type, that being specificity/ accuracy. The parameter of specificity/accuracy assesses 


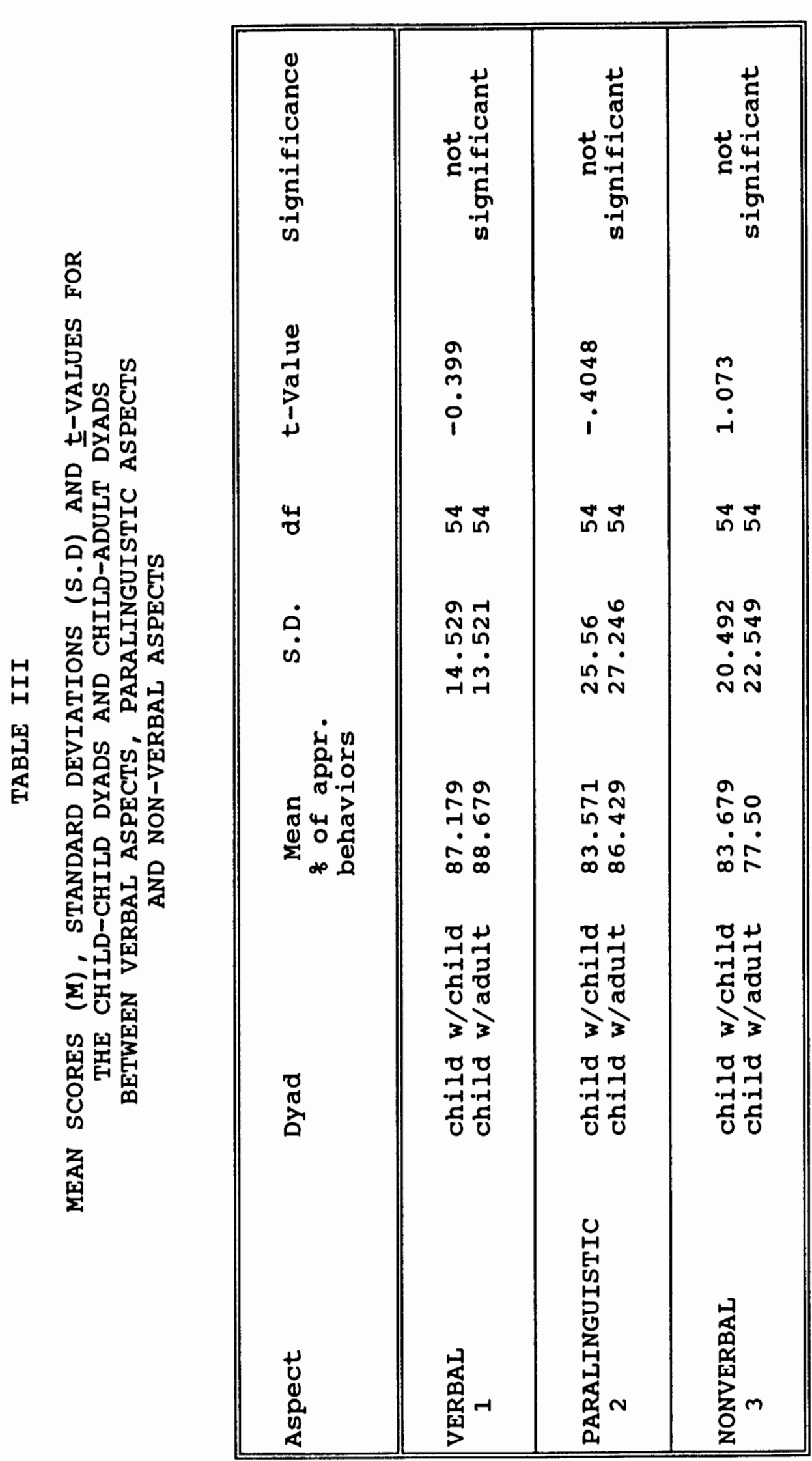


the child's ability to use vocabulary that is appropriate and accurate for the situation, with vocabulary that clearly conveys information in the discourse. The emotionally disturbed children tended to lack use of specified referents, e.g., often using such words as "stuff" and "that," resulting in ambiguity of the message.

The second most frequently inappropriate parameter used by both dyad types was cohesion or connectedness of text. The listener may find it difficult to follow emotionally disturbed children's topic of discourse because their conversation tends to be disjointed, with utterances that are not related in a logical and sequential manner.

The parameter of quantity/conciseness was also frequently inappropriate for both dyad groups. The emotionally disturbed subjects displayed pause time that was too long or too short, resulting in overlap or interruptions, little or no feedback to the speaker, and an inability to produce comments that are relevant and informative.

Vocal quality under Paralinguistic Aspects was also marked inappropriate, within the top five percentage of errors, for both dyad types. A hoarse vocal quality was noted in 8 out of the 28 subjects. This examiner has noted that at a certain phase of the emotionally disturbed children's residential stay, they have a tendency to misuse and strain their vocal mechanism in time-out situations. 
When compared to the child-to-adult dyads, the child-to-child dyads had a larger number of parameters marked inappropriate under the nonverbal aspects, including body posture, eye gaze, and physical proximity. An explanation for this may be, that as emotionally disturbed children, they have more difficulty understanding social rules when they pertain to peers. These children are more apt to use behaviors that detract from the content of the message rather than support and regulate discourse, such as making faces, hitting, or moving into another child's space.

The first two areas of most frequently inappropriate parameters for the two dyads, specificity/accuracy and cohesion, may be indicators of a more serious deficit in the area of language content. Emotionally disturbed children may have vocabulary that falls within the normal range when looking at words in isolation. However, their ability to use that vocabulary to help them convey a message or intent in conversation may be impaired. These emotionally disturbed children have difficulty with basic language relationships (agent, action, object) which is often the basis for the impaired system.

The present study confirms the consensus found in the review of literature, (Allen and Oliver, 1982; Allen and Wasserman, 1985; Baker, Cantwell, and Mattison 1980; Camarata, Hughes, and Ruhl, 1988) that there is a high correlation between behavioral/emotional disorders and 
language delays/disorders. Intervention programs in treatment facilities or self-contained classroom settings have traditionally focused on emotional/social issues. These programs do not routinely emphasize language management or intensive language stimulation. Academic growth, a large component of self-esteem, is facilitated by language skills and strategies. Meeting language needs must be as much of a focus as emotional issues in order to facilitate social/emotional and academic growth.

The Pragmatic Protocol can serve as a probe measurement to ascertain growth of language skills. It was not intended to be an in-depth diagnostic tool, but rather a descriptive taxonomy that can be used to identify a range of pragmatic deficits. It appears to answer the need for which it was developed. In addition, the pragmatic Protocol can provide an easy screening instrument to determine a need for further assessment of language skills. 


\section{CHAPTER V \\ SUMMARY AND IMPLICATIONS}

\section{SUMMARY}

Communication refers to the conveyance of intended messages so that the listeners' attitudes, beliefs, or behaviors are changed (Arwood, 1983). Communication through a language system may be thought of as the integration of the three components of content (semantics), form (syntax), and use (language in context or pragmatics). The coming together of content, form, and use in signs, words, phrases, and discourse is the essence of language development. The synergism of content/form/use makes up language competence or knowledge. When children speak and understand a message, they have a plan that is knowledge of language and they use that plan for the behavior involved in speaking or understanding messages (Arwood, 1983; Bates, 1976; Bloom and Lahey, 1978).

A review of the literature at this time, finds an association between deficient language skills and children who are emotionally disordered. From their review of studies, Baltax and Simmons (in Schiefelbusch and Lloyd, 1988), noted that the "domain of emotional disorders has only begun to be explored with respect to identifying 
pragmatic disorders." The authors contend that children who suffer from lags, deficits, or disorders in emotional development may be at risk for pragmatic development. With the exception of a published literature review of studies of pragmatic deficits in emotionally disturbed children by Baltax and Simmons (in Prizant, Audet, Burke, Hummel, Maher, and Theadore, 1990), there is little research that deals specifically with a pragmatic checklist and the appropriate and inappropriate pragmatic behaviors of emotionally disturbed children.

The purposes of this study were to compare, by use of the Pragmatic Protocol, the incidence of pragmatic disorders within a school-aged, emotionally disturbed population as compared to a control group of normal students and to specify the pragmatic areas, i.e., verbal aspects, paralinguistic aspects and nonverbal aspects, in which deficits occur.

The twenty-eight, 6 to 10 year old subjects were students from the three-room school building housed on the grounds of a residential treatment facility in Multnomah County. All the subjects presented with normal intelligence and hearing acuity. The subjects were observed by way of videotaped conversations in two types of dyads. One conversational dyad was with a peer, another student at the treatment facility; the other conversational dyad was with a familiar adult, this investigator. Observation of the 
videotapes was then used to judge the pragmatic behaviors of the subjects as being appropriate or inappropriate utilizing the Pragmatic Protocol.

The subjects were compared with a normal group, from a study conducted by Prutting and Kirchner (1987), who demonstrated a low incidence of pragmatic deficits (less then $1 \%$ ). The emotionally disturbed students demonstrated a significantly higher incidence of pragmatic deficits, $(x=$ $19 \%$ in child-to-child dyads and $11 \%$ in child-to-adult dyads), with the highest percentage of inappropriate pragmatic behaviors for both dyads being specificity/ accuracy and cohesion. Also within the top five highest percentage of error for both dyads were quantity/ conciseness, eye gaze, and vocal quality. However, there was no significant difference of the percentage of errors across the three aspects (verbal, paralinguistic, and nonverbal scales). In addition, emotionally disturbed children scored consistently on the Pragmatic Protocol regardless of conversational partner.

The findings from this sample, in both dyad types, support the literature which reports a high incidence of language disorders for emotionally disturbed children. Pragmatic skills are more inappropriate in this group compared to a group of normal students. Therefore, pragmatics is an important component of communicative 
competence to be considered in evaluation as well as remediation of communication disorders.

\section{IMPLICATIONS}

\section{Clinical Implications}

A review of literature and the results from this study indicate emotionally disturbed children are an "at risk" population for language disordered skills. Yet, in a study by Camarata, Hughs, and Ruhl (1988) fewer then $6 \%$ of a group of children labeled mild to moderately behavior disordered had been seen for services by a speech-language pathologist and none had received formal language assessment. Across disciplines most professionals who deal with at-risk children would agree that early intervention is the strategy of choice for young children with emotional/ behavioral disorders and/or language disorders.

Children with behavioral problems and/or histories of abuse need to be considered for a speech-language evaluation by a qualified speech-language pathologist to determine individual performance and a course of intervention if preventative measures are to be taken. A pragmatic checklist, such as Prutting's Protocol, can serve as a screening tool with a minimum of time commitment by the speech/language pathologist.

Pragmatics serves as a measure of language competence, with content being the basis for growth. Emotionally 
disturbed children should be given the opportunity to engage in a language enriched curriculum in which they are encouraged to speak, draw, and write about events. Emotionally disturbed children in self-contained classrooms present the speech-language pathologist with an opportunity to present large group activities within the structure of the classroom. A language "theme" presented by a speech-language pathologist can then be incorporated into classroom curriculum/activities.

\section{Research Implications}

There is a need for further research in the area of language skills of the emotionally disturbed. The emotionally disturbed, school-aged child is a component of every school population, whether or not they are enrolled in a self-contained setting or mainstreamed in regular classrooms. In order for these children to reach academic potential and develop age-appropriate social skills, the speech-language pathologist must provide them with the means to reach communicative competence. The more understanding speech-language pathologists have of the effects of abuse, neglect, etc., on language development, the better equipped they will be to facilitate growth.

Information generated by this study could be expanded by future studies examining the pragmatic abilities of emotionally disturbed children as they talk with their classroom teachers, unfamiliar persons, normal peers, etc. 
compared to conversation with a speech-language pathologist. context could also be changed, e.g., doing dyad observations in the classroom or in the treatment setting.

There is also a need to obtain normative data in conjunction with this protocol if it is to be used to screen and measure the use of appropriate speech and language skills in the various contexts of daily living.

Future studies should include the use of other pragmatic instruments to substantiate these findings, as well as expand information on emotionally disturbed children and their language use. 
REFERENCES

Allen, R., and oliver, J. (1982). The effects of child mal-treatment and language development. Child Abuse and Neglect, 6, 299-305.

Allen, R. and Wasserman, G.A. (1985). Origins of language delay in abused infants. Child Abuse and Neglect, 9, 335-340.

Arwood, E. (1983). Pragmaticism: theory and application. Rockville: Aspen Publication.

Austin, J. (1962). How to do things with words. London: oxford University Press.

Baker, L., and Cantwell, D. (1982). Psychiatric disorder in children with different types of communication

disorders. Journal of Communication Disorders, 15, 113-126.

Baker, L., Cantwell D., and Mattison, R. (1980). Behavior problems in children with pure speech disorders and in children with combined speech and language disorders. Journal of Abnormal Child Psychology, 2, 245-256.

Bates, E. (1976). Pragmatics and sociolinguistics in child language. In D. Morehead and A. Morehead (Eds.), Normal and Deficient Child Lanquage. Baltimore: University Park Press.

Bates, E. (1979). Intentions, conventions and symbols. In J. Nicholson (Ed.), Pragmatic Conversational skills of Young Adults in Normal, EMR and TMR Classrooms.

Published master's thesis, Portland State University, Portland.

Bayley, N. (1969). Bayley scales of infant development. New York: Psychological Corporation.

Bloom, L., and Lahey, M. (1978). Language Development and Language Disorders. New York: John Wiley \& Sons.

Bruner, J. (1975). The ontogenesis of speech acts. Journal of Child Language, $2,1-19$. 
Camarata, S., Hughes, C., and Ruhl, K. (1988).

Mild/moderate behaviorally disordered students: A population at risk for language disorders. Language speech \& Hearing Services in Schools, 19, 191-199.

Dore, J. (1975). A pragmatic description of early language development. Journal of Psycholinguistic Research, 4, 343-350.

Gallaher, T., and Prutting, C. (1983). Pragmatic assessment and intervention issues in language. San Diego: College-Hill Press.

Gleason, J. (1985). Studying language development. In J. Berko Gleason (Ed). The Development of Language, pp. 1-33. Columbus: Charles E. Merrill Publishing Co.

Leonard, L., and Reid, L. (1979). Children's judgments of utterance appropriateness. Journal of Speech and Hearing Research, 22, 500-515.

Lucas, K. (1983). pragmatic deficits in normal, articulation disordered, and language delayed samples. Published master's thesis, Portland State University, Portland.

Miller, L. (1978). Pragmatics and early childhood language development: Communicative interactions in a half-hour sample. Journal of Speech and Hearing Disorders, 43, 419-436.

Nicholson, J. (1983). Pragmatic conversational skills of young adults in normal, EMR, and TMR classrooms.

Published master's thesis, Portland State University, Portland.

ornitz, E. and Ritvo, E. (1976). The syndrome of autism: A critical review. American Journal of Psychiatry, 133

(6), 609-621.

Parnell, M., and Amerman, J. (1983). Answers to wh-questions: research and application. In $T$. Gallagher and C. Prutting (Eds.), Pragmatic assessment and intervention issues in language. pp. 129-150. San Diego: College-Hill Press.

Prizant, B., Audet, L., Burke, G., Hummel, L., Maher, S., and Theadore, G. (1990). Communication Disorders and Emotional/Behavioral Disorders in Children and Adolescents. Journal of Speech and Hearing Disorders, $55,179-191$ 
Prutting, C. (1982). Pragmatics as social competence. Journal of Speech and Hearing Disorders 47, 123-134.

Prutting, C. amd Kirchner, D. (1987). A clinical appraisal of pragmatic aspects of language. Journal of Speech and Hearing Disorders, 52, 105-199.

Rutter, M. (1983). Cognitive deficits in the pathogenesis of autism. Journal of Child Psychology and Psychiatry, $24(4), 513-531$.

Schiefelbusch, R., and Lloyd, L. (1988). Language perspectives: Acquisition, retardation, and intervention. Austin: Pro-Ed.

Schwabe, A., and Olswang, L., and Kriegsmann, E. (1986). Requests for information: Linguistic, cognitive, pragmatic, and environmental variables. Language, speech, and Hearing Services in Schools, 17, 38-55.

Searle, J. (1969). Speech acts: An essay in the philosophy of language. Cambridge: University Press.

Shapiro, T. Chiarandini, I., \& Fish, B. (1974). Thirty severely disturbed children. General Psychiatry, 30, 819-825.

Shapiro, T. Huebner, F. (1976) speech patterns of five psychotic children now in adolescence. Journal of the American Academy of child Psychiatry, 15, 278-293.

Warren-Leubecker, A., and Bohannon, J. (1985). Language in society: variation and adaptation. In J. Berko Gleason (Ed.) The developmentment of lanquage, pp. 173-217. Ohio: Charles E. Merrill Publishing Co.

Wiig, E. (1982). "Let's talk": Developing pro-social communication skills. Columbus: Charles E. Merrill. 
APPENDIX A

PRAGMATIC PROTOCOL 
APPENDIX A

PRAGMATIC PROTOCOL

NAME :

DATE :

COMMUNICATIVE

SETTING OBSERVED

COMMUNICATIVE PARTNER'S RELATIONSHIP

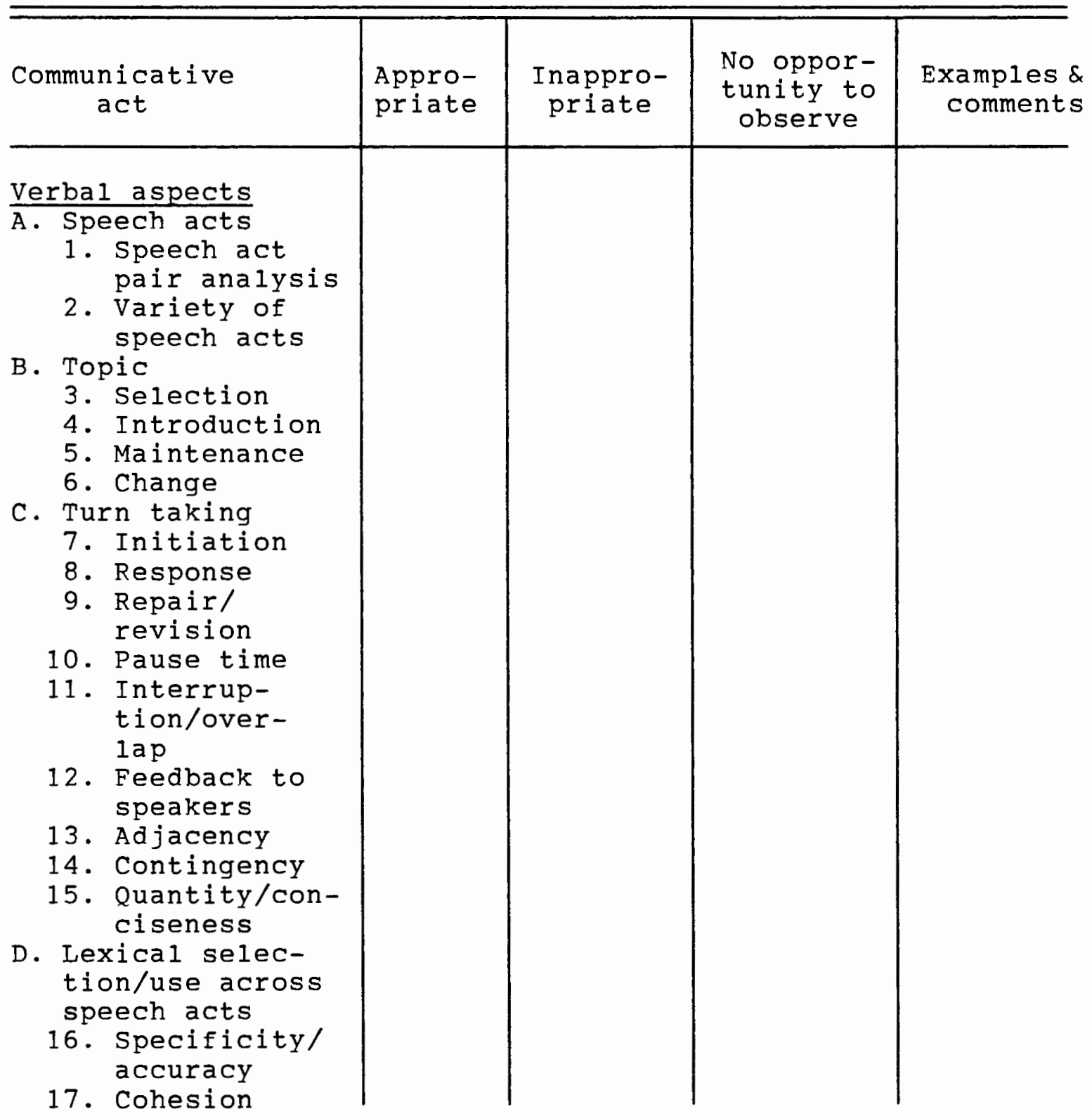




\begin{tabular}{|c|c|c|c|c|}
\hline $\begin{array}{c}\text { Communicative } \\
\text { act }\end{array}$ & $\begin{array}{l}\text { Appro- } \\
\text { priate }\end{array}$ & $\begin{array}{c}\text { Inappro- } \\
\text { priate }\end{array}$ & $\begin{array}{l}\text { No oppor- } \\
\text { tunity to } \\
\text { observe }\end{array}$ & $\begin{array}{c}\text { Examples } \delta \\
\text { comments }\end{array}$ \\
\hline $\begin{array}{l}\text { E. Stylistic vari- } \\
\text { ations } \\
\text { 18. The varying } \\
\text { of communica- } \\
\text { tive style } \\
\text { Paralinguistic } \\
\text { aspects } \\
\text { F. Inteligibility } \\
\text { and prosodics } \\
\text { 19. Intelligi- } \\
\text { bility } \\
\text { 20. Vocal inten- } \\
\text { sity } \\
\text { 21. Vocal } \\
\text { quality } \\
\text { 22. Prosody } \\
\text { 23. Fluency } \\
\text { Nonverbal } \\
\text { aspects } \\
\text { G. Kinesics and } \\
\text { proxemics } \\
24 . \text { Physical } \\
\text { proximity } \\
\text { 25. Physical } \\
\text { contacts } \\
\text { 26. Body posture } \\
27 \text {. Foot/leg and } \\
\text { hand/arm } \\
28 \text {. Gestures } \\
29 \text {. Facial } \\
\text { expression } \\
\text { 30. Eye gaze }\end{array}$ & & & & \\
\hline
\end{tabular}

SOURCE: C. Prutting and D. Kirchner, A clinical appraisal of pragmatic aspects of language. Journal of Speech and Hearing Disorders, 52, (1987): 105-199. 
APPENDIX B

DEFINITIONS FOR COMMUNICATIVE PARAMETERS ASSESSED USING THE PRAGMATIC PROTOCOL 


\begin{abstract}
APPENDIX B
DEFINITIONS FOR COMMUNICATIVE PARAMETERS ASSESSED

USING THE PRAGMATIC PROTOCOL
\end{abstract}

VERBAL ASPECTS

Speech act pair analysis

The ability to take both speaker and listener role appropriate to the context. Types: Directive/compliance-personal need, imperatives, permissions, directives, question directives, and hints. Query/response--request for confirmation, neutral requests for repetition, requests for specific constituent repetition. Request/response--direct request, inferred requests, requests for clarification, acknowledgment of request for action. Comment/acknowledgment--description of ongoing activities; of immediate subsequent activity; of state or condition of objects or person; naming; acknowledgments that are positive, negative, expletive, or indicative.

Examples: Appropriate behaviors: Initiates directives, queries, and comments; responds to directives by complying; responds to queries; responds appropriately to requests; and acknowledges comments made by the speaker. Appropriate behavior can be verbal or nonverbal as in the case of taking appropriate action to a directive or request. Inappropriate behaviors: Does not initiate directives, queries, and comments; does not respond to directive, requests, or queries by the speaker; and does not use acknowledgments made by the speaker either nonverbally or verbally.

Variety of speech acts

The variety of speech acts or what one can do with language such as comment, assert, request, promise, and so forth. Examples: Appropriate behaviors: The partner shows both appropriate use of and diversity in the number of different speech acts he can accomplish. Inappropriate behaviors: The partner shows inappropriate use or a reduced range of different speech acts he or she can use (e.g., a particular child whose productive repertoire is restricted to requests for objects with no other observed speech act types). 
Topic

a. Selection

b. Introduction

c. Maintenance
The selection of a topic appropriate to the multidimensional aspects of context. Introduction of a new topic in the discourse.

Coherent maintenance of topic across the discourse.

d. Change Change of topic in the discourse.

Examples: Appropriate behaviors: The speaker/listener is able to make relevant contributions to a topic, is able to make smooth changes in topic at appropriate times in the discourse, is able to select appropriate topics for discussion given the context and participants, and is able to end discussion of a topic at an appropriate place in the discourse. Inappropriate behaviors: The introduction of too many topics within a specified time limit, the inability to initiate new topics for discussion, the inability to select appropriate topics for discussion given the context and participants, and the inability to make relevant contributions to a topic. Inability to maintain topic may frequently co-occur with high frequency of new topic introductions.

Turn taking

$$
\begin{aligned}
& \text { a. Initiation } \\
& \text { b. Response } \\
& \text { c. Repair/ } \\
& \text { revision }
\end{aligned}
$$

a. Pause time

e. Interruption/ overlap

f. Feedback to Iistener

g. Adjacency

h. Contingency

i. Quantity/ conciseness
Smooth interchanges between speaker/ 1 istener.

Initiation of speech acts.

Responding as a listener to speech acts.

The ability to repair a conversation when a breakdown occurs, and the ability to ask for a repair when misunderstanding or ambiguity has occurred.

Pause time that is too short or too long between words, in response to a question, or between sentences.

Interruptions between speaker and 1 istener; overlap refers to two people talking at once.

Verbal behavior to give the 1 istener feedback such as yeah and really; nonverbal behavior such as head nods to show positive reactions and side to side to express negative effects or disbelief.

Utterances that occur immediately after the partner's utterance.

Utterances that share the same topic with a preceding utterance and that add information to the prior communicative act.

The contribution should be as informative as required but not too informative. 
Examples: In all of the above categories, appropriate and inappropriate behavior is judged in relationship to both speaker and listener in the dyad. Appropriate behaviors: Initiating conversation and responding to comments made by the speaker, asking for clarification when a portion of the message is misunderstood and revising one's own message to facilitate understanding, avoiding interrupting or talking before the other partner is finished, giving feedback to the speaker as a way of moving the conversation forward, appropriate length of pauses in the conversation to support timing relationships in the conversation, and making comments relevant and informative. Inappropriate behaviors: Little initiation in the conversation forcing one partner to take the burden of moving the conversation forward, no response of inappropriate responses to requests for clarification by the partner, no attempt to ask for repair, long pauses that interrupt timing relationships in the conversation, pause time that is too short and results in overlap or interruptions, little or no feedback to the speaker, and inability to produce comments that are relevant and informative.

Lexical selection/

use

Specificity/

Accuracy

Lexical items of best fit considering the text.

Examples: Appropriate behaviors; The ability to be specific and make appropriate lexical choices to clearly convey information in the discourse. Inappropriate behaviors: Overuse of unspecified referents that results in ambiguity of the message. Also includes inappropriate choice of lexical items that do not facilitate understanding. 